${ }^{2}$ University Hospital Montpellier, Rheumatology, Montpellier, France; ${ }^{3}$ University Hospital Clermont-Ferrand, Rheumatology, Clermont-Ferrand, France; ${ }^{4}$ University Hospital Montpellier, Clinical research and epidemiology unit (Department of Medical Information), Montpellier, France; ${ }^{5}$ Hospital Le Mans, Rheumatology, Le Mans, France; ${ }^{6}$ University Hospital of Tours, Department of Rheumatology and CIC INSERM 1415, Tours, France: ${ }^{7}$ University of Tours, EA 7501, GICC, Tours, France

Background: Anti-TNF treatments (TNFi) have shown high efficacy in axial spondyloarthritis (ax-SpA) with inadequate response to non-steroidal anti-inflammatory drugs (NSAIDs). However their effect remains predominantly symptomatic, and their long-term tolerance as well as significant societal cost justify investigation about a potential reduction in drug dosage, or -most feasible and comfortable for the patient- increase in intervals between doses.

Objectives: To assess if a progressive and monitored reduction of administered TNFi by increase of intervals between injections results in a comparable proportion of patients remaining after 12 months $(m)$ in low disease activity state despite a decreased cumulative treatment dose received.

Methods: Non-inferiority randomized controlled trial, having included adult patients with ax-SpA fulfilling ASAS criteria, already treated by anti-TNF, and in stable low disease activity for at least $6 \mathrm{~m}$ (current and at least $6 \mathrm{~m}$ old BAS$\mathrm{DAl}<4 / 10$ ), who were randomized into 2 groups: either keeping on their usual treatment with stable doses ("unchanged" group), or progressive spacing of injections of their treatment ("spacing" group). Follow-up was done every $3 \mathrm{~m}$ during $12 \mathrm{~m}$, with regular monitoring of disease activity and, in patients from the group "spacing", modification of the rhythm of injections according to disease activity and predefined standardized protocol (either increase or decrease (stepback) of intervals between injections). The primary endpoint was the difference of proportions of patients having a low disease activity state (BASDAl $<4 / 10)$ after $12 \mathrm{~m}$ of follow-up between the 2 groups. It was estimated on the ITT population after multiple imputation. The $90 \%$ confidence interval associated was calculated using the Farrington-Manning method and the lower bound was compared to the non-inferiority margin of $-20 \%$. With an expected proportion of $85 \%$ patients remaining in low disease activity in the unchanged group, and $\alpha$ and $\beta$ risks at respectively $5 \%$ and $90 \%$, the required number of patients was calculated at 358 , and thus 398 had to be included with a $10 \%$ expected proportion of patients with unavailable data.

Results: 398 patients were randomized in 23 French rheumatology units (197 and 201 in the spacing and unchanged groups respectively), and 389 included in analyses (9 did not receive the allocated treatment). Mean (SD) age was 44.3 (12.4) years, $71.2 \%$ were males. Mean (SD) BASDAI at inclusion was 1.45 (1.02). TNFi used were etanercept $(35.7 \%)$, adalimumab $(33.9 \%)$, infliximab $(20.6 \%)$, golimumab (9.3\%) and certolizumab (0.5\%). For the 373 patients with complete follow-up (93.7\%), 162/184 (88.0\%) had a low disease activity in the "spacing" group vs. 173/189 (91.5\%) in the "unchanged" group at $12 \mathrm{~m}$. After multiple imputation for the 16 patients with missing data, the difference of proportion between the two groups was estimated to $-4.18 \%$ [CI90\% $-10.0 ; 1.7]$, thus confirming the non-inferiority of the "spacing" procedure. In the "spacing" group at $12 \mathrm{~m}, 134 / 162$ $(82.7 \%)$ patients in low disease activity were still receiving a lowered TNFi dose. Conclusion: In ax-SpA patients with BASDAl $<4$ for at least 6 months under $\mathrm{TNFi}$, it is possible to increase intervals between injections while maintaining a low disease activity by adjusting treatment with quarterly monitoring of $\mathrm{SpA}$ activity.

Disclosure of Interests: Cédric Lukas Speakers bureau: Abbvie, Amgen, Janssen, Lilly, MSD, Novartis, Pfizer, Roche-Chugai, UCB, Consultant of: Abbvie, Amgen, Janssen, Lilly, MSD, Novartis, Pfizer, Roche-Chugai, UCB, Grant/ research support from: Pfizer, Novartis and Roche-Chugai, Anne Tournadre Speakers bureau: Abbvie, Fresenius, Janssen, MSD, Pfizer, Roche Chugai, Sanofi, Paid instructor for: Fresenius, Consultant of: Abbvie, Fresenius, Lilly, Novartis, Sanofi, Grant/research support from: Fresenius, Novartis, Pfizer, UCB, Marie Christine Picot: None declared, Erika Nogué: None declared, Emmanuelle Dernis Speakers bureau: Roche chugai, UCB, BMS, Novartis, Lilly, Mylan, Pfizer, Celgène, Consultant of: UCB, MSD, BMS, Lilly, Novartis, Philippe Goupille Speakers bureau: AbbVie, Amgen, Biogen, BMS, Celgene, Chugai, Janssen, Lilly, Medac, MSD, Nordic Pharma, Novartis, Pfizer, Sanofi and UCB, Consultant of: AbbVie, Amgen, Biogen, BMS, Celgene, Chugai, Janssen, Lilly, Medac, MSD, Nordic Pharma, Novartis, Pfizer, Sanofi and UCB, Grant/research support from: AbbVie, Amgen, Biogen, BMS, Celgene, Chugai, Janssen, Lilly, Medac, MSD, Nordic Pharma, Novartis, Pfizer, Sanofi and UCB, Bernard Combe Speakers bureau: AbbVie; Bristol-Myers Squibb; Gilead; Janssen; Lilly; Merck; Novartis; Pfizer; Roche-Chugai; and Sanofi, Consultant of: AbbVie; Bristol-Myers Squibb; Gilead; Janssen; Lilly; Merck; Novartis; Pfizer; Roche-Chugai; and Sanofi, Grant/ research support from: Novartis, Pfizer, and Roche-Chugai, Jacques Morel Speakers bureau: Abbvie, Biogen, BMS, Fresenius Kabi, Lilly, Mylan, Novartis, Pfizer, Sanofi, Consultant of: Abbvie, BMS, Boerhinger Ingelheim, Galpaagos, GSK, Lilly, Novartis, Sanofi

DOI: 10.1136/annrheumdis-2021-eular.1354

\section{OP0139 \\ A TIME-SHIFTED EFFECT OF TUMOR NECROSIS FACTOR INHIBITORS ON RADIOGRAPHIC SPINAL PROGRESSION IN PATIENTS WITH AXIAL SPONDYLOARTHRITIS: LONG-TERM RESULTS FROM THE GERMAN SPONDYLOARTHRITIS INCEPTION COHORT}

D. Poddubnyy ${ }^{1,2}$, V. Rios Rodriguez ${ }^{1}, M^{2}$. Torgutalp ${ }^{1}$, A. Dilbaryan ${ }^{1}$, M. Verba $^{1}$, F. Proft ${ }^{1}$, M. Protopopov ${ }^{1}$, J. Rademacher ${ }^{1}$, H. Haibel ${ }^{1}$, J. Sieper ${ }^{1}$, M. Rudwaleit ${ }^{3}$. ${ }^{1}$ Charité - Universitätsmedizin Berlin, Division of Gastroenterology, Infectious Diseases and Rheumatology, Berlin, Germany; ${ }^{2}$ Deutsches RheumaForschungszentrum Berlin (DRFZ), ein Institut der Leibniz-Gemeinschaft, Epidemiology Unit, Berlin, Germany; ${ }^{3}$ Klinikum Bielefeld Rosenhöhe, Department of Internal Medicine and Rheumatology, Bielefeld, Germany

Background: There are inconclusive data on the effect of tumor necrosis factor inhibitors (TNFi) on radiographic spinal progression in axial spondyloarthritis (axSpA). Although inflammation and new bone formation are linked in $\operatorname{axSpA}$, TNFi failed to show inhibition of radiographic spinal progression over two years compared to historical cohorts in pivotal studies in radiographic axSpA. Subsequent observational studies suggested that a longer treatment duration, earlier treatment initiation and effective inflammation suppression might be required to achieve inhibition of radiographic progression.

Objectives: The aim of the current study was to evaluate the effect of TNFi on radiographic spinal progression in patients with early axSpA in a long-term inception cohort.

Methods: A total of 266 patients with early axSpA (with r-axSpA with symptom duration $\leq 10$ years and nr-axSpA with symptom duration $\leq 5$ years) from the German Spondyloarthritis Inception Cohort (GESPIC) with at least two sets of spinal radiographs obtained at least 2 years apart during a 10-year follow-up were included. These patients contributed with a total of 5422 -year radiographic intervals. Spinal radiographs were evaluated by three trained and calibrated readers according to the modified Stoke Ankylosing Spondylitis Spine Score (mSASSS). The final mSASSS was calculated as a mean of three reader scores. The association between the current TNFi, previous TNFi and radiographic spinal progression defined as the absolute mSASSS change score over 2 years was analyzed using longitudinal generalized estimating equations (GEE) analysis.

Results: Only 9 patients were treated with a tumor necrosis factor inhibitor (TNFi) at baseline, and a total of 77 patients received TNFi during the entire follow-up period that gave 1032 -year intervals covered by TNFi of any duration, and 78 intervals covered by TNFi with treatment duration of at least 12 months. Radiographic spinal progression in axSpA patients receiving TNFi in the current 2-year interval was not different from progression in patients not treated with TNFi, while TNFi in the previous 2-year interval was associated with lower progression compared to patients without TNFi in this interval (Figure 1). The latter was also evident for patients who received TNFi in both previous and current 2-year intervals, i.e. patients treated with TNFi over 4 years. The longitudinal GEE analysis confirmed no significant association between current TNFi treatment and radiographic spinal progression but a significant association between TNFi in the previous 2-year interval (especially if this was continued also in the current interval giving 4 years in total) and the progression in the current one (Table 1)

Table 1. The association between the change of the mSASSS over two years and current and/or previous treatment with TNFi in the longitudinal generalized estimation equation analysis.

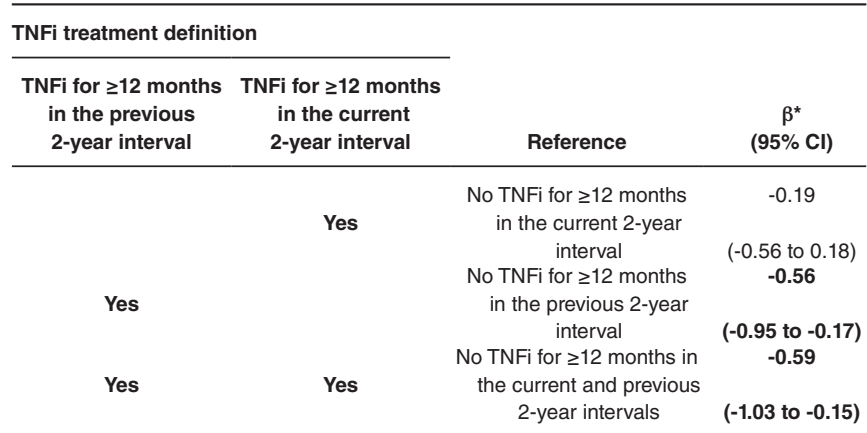

*Parameter estimates from the multivariable models adjusted for sex, symptom duration at the beginning of the current 2-year interval, time-averaged ASDAS in the current 2-year interval, smoking in the current 2-year interval, classification as non-radiographic or radiographic axSpA, and mSASSS at the beginning of the current 2-year interval.

Conclusion: TNFi treatment exhibits a time-shifted inhibitory effect on radiographic spinal progression in axSpA that becomes evident only in the second 2-year interval after treatment initiation. 
Acknowledgements: GESPIC was initially supported by the BMBF. As consequence of the funding reduction by BMBF according to schedule in 2005 and stopped in 2007 , complementary financial support has been obtained also from Abbott, Amgen, Centocor, Schering-Plough, and Wyeth. Starting from 2010, the core GESPIC cohort was supported by AbbVie.

Figure 1. Cumulative probability plots depicting mSASSS change scores over 2 years in patients with axial spondyloarthritis treated vs. not treated with TNFi in the current (A) or previous (B) 2-year interval.

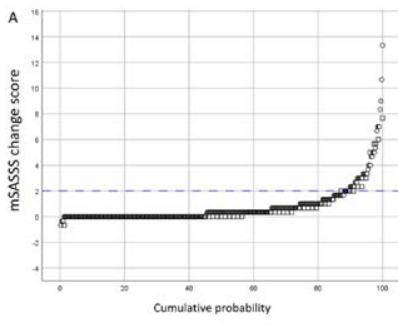

INFi for 212 months in the current 2 -year interval
ONo TNFi for 212 months in the current 2 -year interval

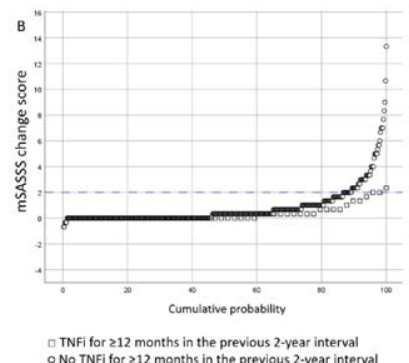

INFi for 212 months in the previous 2 -year interval
ONo TNFi for 212 months in the previous 2 -year intervat

Disclosure of Interests: Denis Poddubnyy Speakers bureau: AbbVie, Bristol-Myers Squibb, Lilly, MSD, Novartis, Pfizer, and UCB, Consultant of: AbbVie, Biocad, Gilead, GlaxoSmithKline, Eli Lilly, MSD, Novartis, Pfizer, Samsung Bioepis, and UCB, Grant/research support from: AbbVie, MSD, Novartis, and Pfizer, Valeria Rios Rodriguez: None declared, Murat Torgutalp: None declared, Ani Dilbaryan: None declared, Maryna Verba: None declared, Fabian Proft: None declared, Mikhail Protopopov: None declared, Judith Rademacher: None declared, Hildrun Haibel: None declared, Joachim Sieper: None declared, Martin Rudwaleit Consultant of: AbbVie, BMS, Celgene, Janssen, Eli Lilly, MSD, Novartis, Pfizer, Roche, UCB Pharma

DOI: 10.1136/annrheumdis-2021-eular.1726

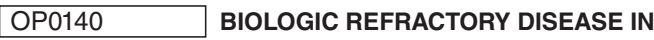 AXIAL SPONDYLOARTHRITIS - DEFINITION, PREVALENCE AND PATIENT CHARACTERISTICS. A COLLABORATION BETWEEN FIVE NORDIC BIOLOGIC REGISTRIES}

D. DI Giuseppe ${ }^{1}$, U. Lindström ${ }^{2}$, K. Aaltonen ${ }^{3}$, H. Relas ${ }^{4}$, S. Aarrestad

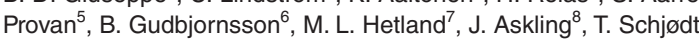
Jørgensen $^{9}$, L. Dreyer ${ }^{10}$, D. Nordström ${ }^{11}$, B. Michelsen ${ }^{12}$, A. J. Geirsson ${ }^{13}$, L. T. H. Jacobsson ${ }^{14}$, B. Glintborg ${ }^{7}{ }^{1}$ Karolinska Institutet, Clinical Epidemiology Division, Department of Medicine Solna, Stockholm, Sweden; ${ }^{2}$ Sahlgrenska Academy at University of Gothenburg, Department of Rheumatology and Inflammation Research, Gothenburg, Sweden; ${ }^{3}$ Ministry of Social Affairs and Health, Pharmaceuticals Pricing Board, Helsinki, Finland; ${ }^{4} \mathrm{Helsinki}$ University Hospital (ROB-FIN), Departments of Medicine and Rheumatology, Helsinki, Finland; ${ }^{5}$ Diakonhemmet Hospital, Department of rheumatology, Oslo, Norway; ${ }^{6}$ Landspitali University Hospital, and Faculty of Medicine, University of Iceland, Centre for Rheumatology Research (ICEBIO), Reykjavik, Iceland; ${ }^{7}$ Center for Rheumatology and Spine Diseases, Centre of Head and Orthopedics, Rigshospitalet, DANBIO and Copenhagen Center for Arthritis Research (COPECARE), Glostrup, Denmark; ${ }^{8}$ Karolinska Institutet, Clinical Epidemiology Division, Dept of Medicine Solna, Stockholm, Sweden ${ }^{9}$ The Parker Institute, Copenhagen University Hospital, Bispebjerg and Frederiksberg, Department of Rheumatology, Copenhagen, Denmark; ${ }^{10}$ Aalborg University Hospital, Department of Rheumatology, Aalborg, Denmark; ${ }^{11} \mathrm{Helsinki}$ University and Helsinki University Hospital, Department of Medicine and Rheumatology, Helsinki, Finland; ${ }^{12}$ Sørlandet Sykehus, Kristiansand, Norway, Division of Rheumatology, Department of Medicine, Kristiansand, Norway;

${ }^{13}$ Reykjavik University Hospital, Department of Rheumatolgy, Reykjavik, Iceland; ${ }^{14}$ Sahlgrenska Academy at University of Gothenburg, Department of Rheumatology and Inflammation Research, Gothenburg, Sweden

Background: In clinical practice, some patients with axial spondyloarthritis (axSpA) fail several consecutive biological treatments (bDMARDs). How this group of "refractory" patients should best be defined, how common they are, and what their characteristics are, is poorly understood.

Objectives: To explore the point prevalence of bDMARD refractory disease in axSpA over time, according to different definitions, and to describe the characteristics of refractory vs. not-refractory patients upon start of their first bDMARD. Methods: Observational prospective cohort study. Patients with axSpA (ankylosing spondylitis/non-radiographic axial SpA) starting a first bDMARD 2009-2018 were identified in biologic registries in Denmark, Sweden, Finland, Norway and Iceland. Clinical characteristics and treatments were retrieved, and data were pooled for analysis.
Refractory disease was defined based on the number of different bDMARD treatments started in individual patients: mild ( $\geq 3$ bDMARDs), moderate $(\geq 4)$, and strict ( 5 or more). Restart of same bDMARD with another bDMARD in between counted as separate courses whereas switch from originator to corresponding biosimilar was ignored.

Proportions of patients fulfilling each definition of refractory disease at 2 and 5 years after the start of 1 st bDMARD were calculated.

Point-prevalence per calendar-year was calculated as the number of patients with refractory disease at the end of each year, divided by the total number of patients ever having starting a first bDMARD before that time-point, and who were still alive and resident in the country.

Results: The point prevalence of refractory axSpA increased with calendar-time (Figure). Among 12,037 included axSpA patients (64\% male), the point-prevalence of bDMARD refractory disease in 2018 was $16 \% / 7 \% / 3 \%$ according to mild/ moderate/strict definitions (Table).

\section{Table 1. Biologic refractory axSpA according to three definitions}

A.Baseline characteristics upon start 1st bDMARD

\begin{tabular}{lcccc}
\hline & & \multicolumn{3}{c}{ Refractory definition } \\
\cline { 3 - 5 } & Overall cohort & MILD & MODERATE & STRICT \\
\hline $\mathrm{N}$ & 12037 & 1969 & 832 & 351 \\
Age, years & $42(13)$ & $41(12)$ & $41(12)$ & $41(12)$ \\
Male, \% & $64 \%$ & $57 \%$ & $54 \%$ & $56 \%$ \\
Disease duration, years & $7(10)$ & $6(9)$ & $6(8)$ & $5(8)$ \\
BASDAl, 0-100 & $53(28)$ & $60(29)$ & $63(27)$ & $66(35)$ \\
ASDAS & $3.3(1.1)$ & $3.5(1.2)$ & $3.6(1.0)$ & $3.7(1.1)$ \\
CRP, mg/L & $16(23)$ & $18(26)$ & $21(28)$ & $23(32)$ \\
Patient global, VAS, 0-100 & $59(25)$ & $65(22)$ & $66(22)$ & $67(23)$ \\
Patient Pain, VAS, 0-100 & $57(24)$ & $62(22)$ & $63(22)$ & $63(22)$ \\
Fatigue, VAS, 0-100 & $59(27)$ & $66(26)$ & $66(26)$ & $68(25)$ \\
B.Proportions of patients having refractory disease 2 and 5 years after start of their first \\
$\quad$ bDMARD & & & & \\
2 years, \% & & $5 \%$ & $1 \%$ & $0 \%$ \\
5 years, \% & $13 \%$ & $4 \%$ & $1 \%$ \\
\hline
\end{tabular}

Numbers are means (SD) unless otherwise stated

Upon start of their $1^{\text {st }}$ bDMARD, patients later fulfilling the definitions for refractory axSpA were more frequently women, had shorter disease duration, higher $\mathrm{C}$-reactive protein and higher patient reported outcomes.

Overall, $5 \% / 1 \% / 0 \%$ had mild/moderate/strict refractory disease 2 years after start of first bDMARD, after 5 years it was 13\%/4\%/1\% (Table).

Conclusion: In this large Nordic observational cohort of axSpA patients treated in routine care, we could demonstrate that a substantial proportion of all patients had used multiple bDMARDs. In 2018 , one in six patients had received $\geq 3$ bDMARDs, indicating a bDMARD refractory disease. Multiple switching was more frequent during later years, probably due to more bDMARDs becoming available. The characteristics of refractory axSpA, including sex and disease activity, will have to be further explored, as will the impact of refractory disease on long-term outcomes.

Acknowledgements: the DANBIO, SRQ, ICEBIO, ROB-FIN and NOR-DMARD registries.

Partly sponsored by Nordforsk and Foreum.

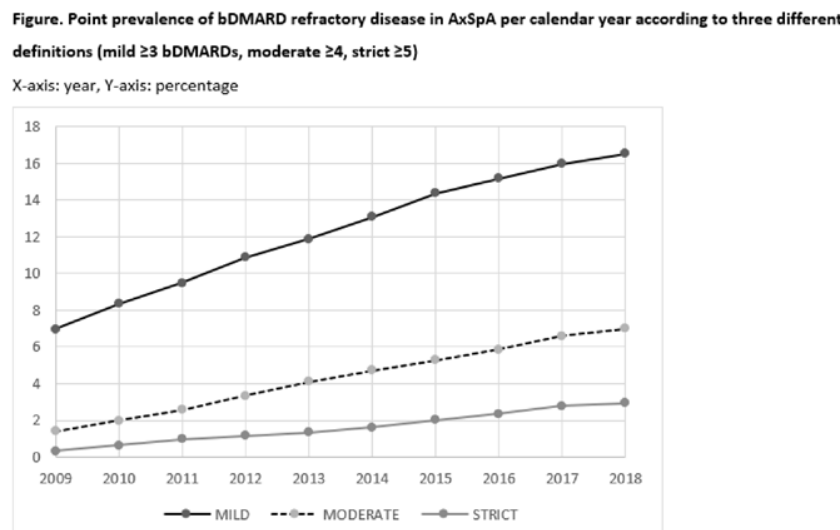

Disclosure of Interests: Daniela Di Giuseppe: None declared, Ulf Lindström: None declared, Kalle Aaltonen: None declared, Heikki Relas Speakers bureau: Abbvie, Celgene, MSD, Roche, Sella Aarrestad Provan: None declared, Björn Gudbjornsson Speakers bureau: Amgen and Novartis, Merete 